\begin{tabular}{l|c|c|}
\hline \hline & International Journal of Current Research in \\
\hline & Biosciences and Plant Biology \\
\hline EXCELLENT \\
PUBLISHERS
\end{tabular}

\title{
Comparative evaluation of phytochemicals in leaf, stem bark and root bark of Holarrhena antidysenterica, Wrightia tomentosa and Wrightia tinctoria
}

\author{
Pawan Kumar Ahirwar ${ }^{*}$, S. P. Mishra ${ }^{2}$ and Pramod Kumar3 \\ ${ }^{1}$ Department of Biological Science, M.G.C.G.V.V, Chitrakoot-485 334, Satna (M.P.), India \\ ${ }^{2}$ Department of Crop Sciences, Faculty of Agriculture, M.G.C.G.V.V., Chitrakoot-485 334, Satna (M.P.), India \\ 3 Genetics and Tree Improvement Division, T.F.R.I., Jabalpur (M.P.), India \\ *Corresponding author; e-mail: ahirwarpawan1289@gmail.com
}

\begin{abstract}
Article Info
Date of Acceptance:

15 September 2020

Date of Publication: o6 October 2020

\section{Keywords}

Allopathic medicine

Herbal medicine

Holarrhena

antidysenterica
\end{abstract}

Phytochemicals

Wrightia tomentosa

Wrightia tinctoria

\section{Introduction}

Plants are powerful resources of bio-chemicals and thus, good source of phytomedicines since ancient times. Natural constituents can be extracted from any part of the plant like leaves, bark, flowers, fruits, seeds, roots, etc. which contain bioactive compounds. The medicinal property of bioactive compounds is the result of the combinations of secondary metabolites present in the plant (Shwetha et al., 2011). Plants have the ability to synthesize aromatic products mainly secondary metabolites such as tannins, terpenoids, alkaloids, flavonoids, etc. of which about 12,000 secondary metabolic compounds have been isolated. These isolated secondary metabolites showed wide range of pharmacological properties such as in-vitro antibacterial and antifungal activities (Zahan et al., 2013). Their major role is in the plant defense system against herbivores, microorganisms and insects. Some are involved in plant pigmentation (tannins and quinines), odour (terpenoids) etc. and thus responsible for a definite physiological effect. It clearly indicates that the medicinal property of plants lie in the 
bioactive phytochemical constituents (Patel et al., 2015). Many secondary metabolites of plants are commercially important and are being used in a number of pharmaceutical compounds (Meenakshi, 2015). Phytochemical investigation of bioactive compounds from plants has led to the discovery of many therapeutic drugs which effectively used in protection and treatment of various diseases including cancer (Sharma et al., 2017). With this background and abundant source of unique active components harbored in plants, the present study was conducted on leaf, stem bark and root bark of three medicinal plants viz., Holarrhena antidysenterica (collected from two locations); Wrightia tomentosa and Wrightia tinctoria. These plant species belong to the family Apocyanaceae.

H. antidysentrica is a small deciduous tree with cream white flowers and found throughout the dry forests of India. The different parts of the plant are used in the indigenous system of medicine. It is used in the treatment of dysentery, diarrhea, helminthic, astringent and haemostatic disorders (Ahirwar et al., 2019).

$W$. tomentosa is an endangered medicinal tree placed in the category I of Red Data (Nagalakshmi and Murthy, 2015) with many medicinal uses. Ethnomedically $W$. tomentosa is widely used to treat stomach ache, tooth ache, fever, hemorrhage, arthritis and snake bite (Srinivas et al., 2013; Ahirwar et al., 2019).

Wrightia tinctoria $\mathrm{R}$. Br. is a small to medium size deciduous tree, which is widely distributed all over India. In South India, it is commonly called as "Jaundice curative tree" traditionally (Dixit et al., 2014). The common name of plant is Paalai and called "Sweet Indrajao". The plant are effective in stomachic, in the treatment of abdominal pain, anti- diarrhoeal and antihaemorrhagic (Deventhiran et al., 2016). Wrightial, cycloartenone, cycloeucalenol, indigotin, indirubin, tryptanthrin, isatin, rutin, $\beta$-sitosterol, $\beta$-amyrin, wrigatiadione are the main isolated compounds from seeds, leaves and bark of this plant (Singh et al., 2015). Reviewed on phytochemical, pharmacological and pharmacognostical profile of $W$. tinctoria and noted its anti-cancer, anti-HIV, and anti-diabetic properties too (Srivastava, 2014). The aim of the present study was investigation of different phytochemicals in selected parts of $H$. antidysenterica, $W$. tomentosa and $W$. tinctoria.

\section{Materials and methods}

\section{Collection of plant samples and powder preparations}

Leaf and stem bark of Holarrhena antidysenterica was collected from Sati Anusuiya area and root bark was collected from Bagdara Ghati of Gupt Godavari area of Chitrakoot forest whereas, leaf, stem bark and root bark of Wrightia tinctoria was collected from Bagdara Ghati of Gupt Godavari area of Chitrakoot forest of Satna district of Madhya Pradesh. Samples of Holarrhena antidysenterica were also collected from Talawada area of Guna district of Madhya Pradesh. While the leaf, stem bark and root bark of Wrightia tomentosa were collected from the Holipur area of Budhni tehsil of Sehore district of Madhya Pradesh and identity was confirmed by Dr. R.L.S. Sikarwar, a taxonomist of Department of Ayurveda Sadan (Research Laboratory), Arogyadham, Deendayal Research Institute (DRI), Chitrakoot, Satna (M.P.) India. Collected plant samples were brought to the laboratory and washed with running tap water, dried under shade and prepared powder with the help of electric grinder. The powder was sieved (No. 43) and stored in air tight closed containers separately for protection from moisture and contamination.

\section{Phytochemical screening}

The powdered material weighing $2.0 \mathrm{~g}$ was extracted in $100 \mathrm{ml}$ ethanol by continuous extraction for 6 hours on rotatory flask shaker and left for 18 hours for maceration. The extract was filtered through Whatman filter paper no. 1 and tested for various classes of active chemical constituents by using standard methods described in Ayurvedic Pharmacopeia of India (API) and "Methods of Biochemical Analysis" (Anonymous 2010; Harborne 1984; Thimmaiah 1999).

\section{Phytochemicals estimation}

Determination of alkaloid, flavonoid, saponins and crude protein by gravimetric method (in \%) and total carbohydrate, soluble protein and 
tannin $(\mathrm{mg} / \mathrm{ml})$ were estimated in three replications by spectrophotometric methods in leaf, stem bark and root bark of three species. Alkaloid was estimated by both gravimetric and spectrophotometric methods.

Alkaloid- Harborne (1973) method was used for the determination of alkaloid.

Flavonoid- Bohm and Kocipai - Abyazan (1994) method was used for the determination of flavonoid.

Saponins- Obadani and Ochako (2001) method was used for the determination of saponins with modification of petroleum ether in place of diethyl ether.

Crude protein- Kel plus method was used for estimation of crude protein (Sadasivam and Manickam 1996).

Sample preparation: Taken $0.5 \mathrm{~g}$ powder of samples in digestion tubes and added punch of digestion mixture and $10 \mathrm{ml}$ of sulphuric acid in all trubes. Sample was digested until green or dark green colour appeared. After cooling of tubes, sample particles attached side of the tubes dissolved with the help of distilled water and total volume of sample maintained to 20ml. Samples were digested until sample residues dissolve completely and homogeneous sample forms. Samples were run in Kel - Plus machine.

Procedure: Added $30 \mathrm{ml}$ of methylene redmethylene blue mixed indicator $(20 \mathrm{ml}$ of methylene red plus $10 \mathrm{ml}$ methylene blue) in $4 \%$ boric acid ( $1970 \mathrm{ml}$ of $4 \%$ boric acid $+30 \mathrm{ml}$ of mixed indicator) and fit the gallon of $4 \%$ boric acid (total volume $2000 \mathrm{ml}$ ) and 40\% sodium hydroxide solution (total volume $2000 \mathrm{ml}$ ) in tubes of acid and alkali solution. Tap water supplied for mixing of ammonia gas. Collected 25 $\mathrm{ml}$ of distillate sample in a conical flask and titrated against $0.1 \mathrm{~N} \mathrm{HCl}$ standard acid solutions until green or blue colour end point reaches. Blank prepared by same procedure with distilled water. Calculated nitrogen $(\mathrm{N})$ content by applying formula:

$$
\% \text { of } \mathrm{N}=\frac{14.1(\mathrm{~B}-\mathrm{S}) \times 0.1 \mathrm{~N} \mathrm{HCl} \times 100}{\text { Weight of sample taken } \times 1000}
$$

Where, B and S represent titration value of blank and sample respectively.

Protein Nitrogen: Total nitrogen value multiplied with 6.25 for crude protein content which also includes non-protein nitrogen.

Total carbohydrate- Total carbohydrate or total soluble sugars estimated by Anthrone method (Thimmaiah, 1999).

Soluble protein- Lowry's method was used for the estimation of soluble protein or true protein (Lowry et al., 1951; Mani et al., 2019; Sadasivam and ManickaM, 1996).

Tannin- Folin-Denis method was used for the estimation of tannin (Sadasivam and ManickaM, 1996; Thimmaiah, 1999).

Alkaloids - Alkaloids was estimated spectrophotometrically by Dragendorff's reagent method (Nayeem et al., 2011).

Sample extract preparation- 109 coarsely powdered plant material was extracted with $25 \mathrm{ml}$ $2 \%$ aqueous acetic acid at room temperature for 10 minute. The procedure was repeated 3 times. All three extracts were mixed and diluted to $100 \mathrm{ml}$ with $2 \%$ aqueous acetic acid.

Procedure for estimation of alkaloids - A 5 $\mathrm{ml}$ amount of the extract was taken and $\mathrm{pH}$ maintained at $2.0-2.5$ with dilute $\mathrm{HCl}$. A $2 \mathrm{ml}$ of DR was added to it, and the precipitate formed was centrifuged. The centrifugate was checked for complete precipitation by adding DR. After centrifugation, the centrifugate was decanted completely and meticulously. The precipitate was further washed with alcohol. The filtrate was discarded and the residue was than treated with 2 ml disodium sulfide solution. The brownish black ppt. formed was than centrifuged. Completion of ppt. was checked by adding two drops of disodium sulfide. The residue was dissolved in $2 \mathrm{ml}$ conc. nitric acid. This solution was diluted to $10 \mathrm{ml}$ in a standard flask with distilled water. $1 \mathrm{ml}$ was then pipette out and $5 \mathrm{ml}$ thiourea solution was added to it. The absorbance was measured at $435 \mathrm{~nm}$ against the blank containing nitric acid and thiourea. The amount of bismuth present in the 
solution was calculated by multiplying the absorbance values with the factor taking suitable dilution factor into consideration. The factor is obtained from the standard curve which is constant for different concentrations.

$$
\text { Factor }=\text { concentration/absorbance. }
$$

\section{Results and discussion}

Preliminary phytochemical screening revealed (Table 1) that resin was present in all samples while saponin and starch was absent in all samples. Alkaloids were observed in all samples except leaf of HALC and WTLC. Carbohydrate was present in all samples except in HALT. Proteins were not observed in HALC, HALT, HARBT, WTLH, WTRBH, WTLC and WTSBC. Flavonoid was found in HALC, WTSBH, and WTLC but absent in all other samples. Steroid was present only in HASBT, HARBT but absent in all other samples. Glycoside was absent in all samples except HALC and WTLC. Whereas, tannins were found present in HALC, HASBC, HARBT, WTLH, WTLC, WTSBC, WTRBC and absent in HARBC, HALT, HASBT, WTSBH and WTRBH. Similar study of leaf of $W$. tinctoria was conducted by Mahendra and Nityanand (2009) and Vedhanarayanan et al. (2013).

Table 1. Qualitative phytochemical screening of ethanolic extract of selected plants.

\begin{tabular}{|c|c|c|c|c|c|c|c|c|c|c|}
\hline \multirow{2}{*}{$\begin{array}{l}\text { Name of } \\
\text { Samples }\end{array}$} & \multicolumn{10}{|c|}{ Name of phytoconstituents } \\
\hline & Alkaloids & Carbohydrate & Proteins & Resins & Saponin & Starch & Flavonoid & Steroid & Glycoside & Tannins \\
\hline HALC & - & + & - & + & - & - & + & + & + & + \\
\hline HASBC & + & + & + & + & - & - & - & + & - & + \\
\hline HARBC & + & + & + & + & - & - & - & + & - & - \\
\hline HALT & + & - & - & + & - & - & - & + & - & - \\
\hline HASBT & + & + & + & + & - & - & - & - & - & - \\
\hline HARBT & + & + & - & + & - & - & - & - & - & + \\
\hline WTLH & + & + & - & + & - & - & - & + & - & + \\
\hline WTSBH & + & + & + & + & - & - & + & + & - & - \\
\hline WTRBH & + & + & - & + & - & - & - & + & - & - \\
\hline W'TLC & - & + & - & + & - & - & + & + & + & + \\
\hline WTSBC & + & + & - & + & - & - & - & + & - & + \\
\hline WTRBC & + & + & + & + & - & - & - & + & - & + \\
\hline \multicolumn{11}{|c|}{ 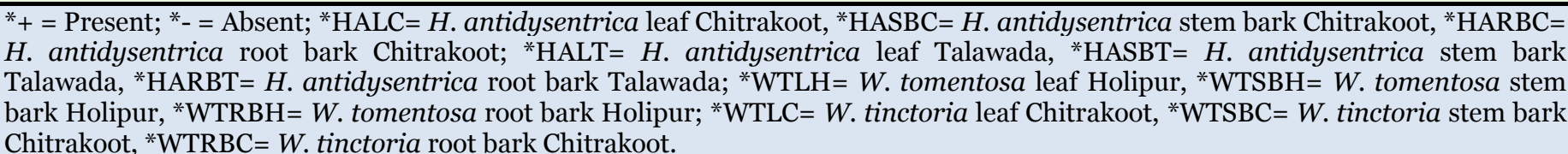 } \\
\hline
\end{tabular}

Average yield of phytoconstituents viz., alkaloid, flavonoid, saponin and crude protein in leaf, stem bark, root bark of $H$. antidysentrica of Chitrakoot and Talawada, $W$. tomentosa of Holipur and $W$. tinctoria of Chitrakoot determined in percentage (\%) by gravimetric method (Table 2). Experimental findings exhibited maximum alkaloids in HALT followed by HASBT, WTLH, WTLC, HALC, WTSBC, WTRBC, HARBT, WTSBH, HARBC, HASBC and WTRBH. Flavonoids were in decreasing order in WTLH, HASBC, HALC, HASBT, HARBC, HALT, WTLC, HARBT, WTSBH, WTRBH, WTRBC and WTSBC. Highest content of saponin was found in HARBT followed by HALT, WTLC, HASBC, WTLH, WTRBH, HASBT, HALC, WTRBC, WTSBH, HARBC and WTSBC whereas, highest contents of crude protein was found in WTRBH followed by WTRBC, WTSBH, WTSBC, HALT, HASBC, WTLC, WTLH, HASBT, HARBT,
HARBC and HALC respectively. Contrast result of alkaloid, saponin and tannin reported by Mahendra and Nityanand (2009). Sharma et al. (2017) also confirm the presence of alkaloids, flavonoids and terpenoids in four species of Wrightia.

Total carbohydrate estimation was done spectrophotometrically by Anthrone method. The linear equation $(\mathrm{y}=\mathrm{mx}+\mathrm{c})$ and correlation coefficient $\left(\mathrm{R}^{2}\right)$ of carbohydrate from calibration curve was $\mathrm{y}=0.127 \mathrm{x}+0.258$ and $\mathrm{R}^{2}=0.957$ recorded. The content of soluble sugar was found highest in HASBT followed by WTRBH, HALT, WTRBC, HARBT, WTLH, HASBC, WTSBC, WTSBH, HARBC and HALC respectively (Table 3). Estimation of soluble protein was carried out by Lowry's method. The calibration curve of protein was equivalent to bovine serum albumin (Fraction 
method). While spectrophotometric method reveals highest content of total carbohydrate, soluble protein, tannin and alkaloids also in HASBT, HALT, HARBC and WTLH. These phytoconstituents are responsible for therapeutic and pharmacological properties of plants and thus makes the plant medicinally more valuable. Root bark and stem bark of these plants are useful in prevention and slowing the progress of various oxidative stress- related diseases or potentially applicable in both medicine as well as to develop nutritionally rich healthy food products by industries at commercial level.

\section{Conflict of interest statement}

Authors declare that they have no conflict of interest.

\section{Acknowledgement}

The first author is thankful to University Grants Commission, New Delhi for awarding Rajiv Gandhi National Fellowship (RGNF) for financial support for conducting this research work and Dr. Manoj Tripathi, Head, Department of Ayurveda Sadan, Arogyadham, Deendayal Research Institute (DRI), Chitrakoot, Satna (M.P.) India for providing necessary facilities.

\section{References}

Abbas, M. N., Rana, S. A., Shahid M., Rana, N., Mahmood-ul-Hassan, M., Hussain M., 2012. Chemical evaluation of weed seeds mixed with wheat grains at harvest. J. Anim. Plant Sci. 22(2), 283-288.

Ahirwar, P. K., Mishra, S. P., Pramod Kumar, Singh, R., Tripathi, I. P., 2019. Pharmacognostical standardization of root bark of Holarrhena antidysenterica (Roth.) Wall. ex A.DC. Int. J. Res. Anal. Rev. 6(2), 800-805.

Dixit, A., Jain, A. K., Tiwari, P., Gupta, N., Gangele, P., 2014. A phytopharmacological review on an important medicinal plant - Wrightia tinctoria. Curr. Res. Pharmaceut. Sci. 4(3), 70-76.

Boham, B. A., Kocipai-Abyazan, R., 1994. flavonoids and condensed tannin from leaves of Hawaiian Vaccinium vaticulatum and $V$. calycinium. Pacific Sci. 48, 458-463.

Deventhiran M., John Wyson, W., Marimuthu, S., Anantha Padmanabhan, S., Saravanan, P.,
Anand, D., Rajarajan, S., 2016. Phytochemical analysis of leaf extracts from Wrightia tinctoria R.Br. and its antidermatophytic activity. Int. J. Pharm. Sci. Rev. Res. 4O(2), 24-27.

Harborne, J. B., 1973. Phytochemical methods. London. Chapman and Hall, Ltd. pp. 49-188.

Harborne, J.J., 1984. Phytochemical methods: a guide to modern techniques of plant analysis, Chapman and Hall, New York, 92, 85.

Khyade, M. S., Vaikos, N. P., 2009. Pharmacognostical and physio-chemical standardization of leaves of Wrightia tinctoria R. Br. Int. J. Pharma Res. Develop. 1-10.

Lowry, O. H., Rosebrough, N. J., Farr, A. L., Randall, R. J., 1951. Protein measurement with the Folin phenol reagent. J. Biol. Chem. 193(1), 265-275.

Meenakshi, V., 2015. Anatomical study of marketed samples of the bark of Holarrhena antidysenterica wall. World J. Pharmaceut. Res. 4(10), 1349-1356.

Nagalakshmi, M. A. H., Sri Rama Murthy, K., 2015. Phytochemical profile of crude seed oil of Wrightia tinctoria R.Br. and Wrightia arborea (Dennst.) Mabb. by GC-MS. Int. J. Pharmaceut. Sci. Rev. Res. 31(2), 46-51.

Nayeem, A. A., Khatun, A., Rahman, M. S., Rahman, M., 2011. Evaluation of phytochemical and pharmacological properties of Mikania cordata (Asteraceae) leaves. J. Pharmacogn. Phytother. 3(8), 118-123.

Neeta, M., Ahirwar, P. K., Mishra, S. P., 2019. Comparative phytochemical analysis of root of Withania somnifera. Science Technology and Society, Department of Sociology Indore Christian college, Indore-452001, India. Gaurav Prakashan University Road, Rewa (M. P.). pp. 53-58.

Obdoni, B. O., Ochuko, P. O., 2001. Phytochemical studies and comparative efficacy of the crude extracts of some Homostatic plants in Edo and Delta States of Nigeria. Global J. Pure Appl. Sci. 8b, 203-208.

Patel, R., Patel, Y., Kunjadia, P., Kunjadia, A., 2015. DPPH free radical scavenging activity of phenolics and flavonoids in some medicinal plants of India. Int. J. Curr. Microbiol. App. Sci. 4(1), 773-780.

Sadasivam, S., Manickam, A., 1996. Biochemical method. New Age International (P) Ltd. Publishers, Second Edition. 
Sharma, A. K., Upadhyaya, S.K., Chauhan, S., Sharma, S., 2017. A comparative phytochemical analysis of Wrightia species of family apocynaceae by spot tests. Int. J. Phytopharm. 7(2), 14-17.

Shwetha, C., Latha, K.P., Pushpa, B., Shruthi, A., Vaidya, V.P., 2011. Phytochemical screening and evaluation of in-vitro antioxidant activity, total phenolics and total flavonoids of Holarrhena antidysentrica leaf extracts. Int. J. Res. Pharm. Chem. 1(3), 546-550.

Singh, R., Kakkar, A., Mishra, V. K., 2015. Phytochemical analysis of Wrightia tinctoria bark extract in water using GC-MS. Int. J. Pharm. Pharm. Sci. 7 (3), 470-472.

Sreevidya, N., Shanta Mehrotra, 2003. Spectrophotometric method for estimation of alkaloids precipitable with dragendorff's reagent in plant materials. J. AOAC Int. 86(6), 1124-1127.

Srinivas, P., Samatha, T., Valya, G., Ragan, A.,
Rama Swamy, N., 2013. Phytochemical screening and antimicrobial activity of leaf extract of Wrightia tomentosa. Int. Res. J. Biol. Sci. 2(3), 23-27.

Srivastava, R., 2014. A review on phytochemical, pharmacological and pharmacognostical profile of Wrightia tinctoria: Adulterant of kurchi. Pharmacogn. Rev. 8(15), 36-44.

Thimmaiah S.K., 1999. Standard methods of biochemical analysis. Kalyani Publishers B-15, sector 8, Noida (U.P.). pp.472-480.

Vedhanarayanan, P., Unnikannan, P., Sundaramoorthy, P., 2013. Antimicrobial activity and phytochemical screening of Wrightia tinctoria (Roxb.) R.Br. J. Pharmacogn. Phytochem. 2(4), 123-125.

Zahan, R., Nahar, L., Alam, Z., Nesa, L., Ekramul Haque, M., 2013. Evaluation of antidiarheal and antidiabetic activities of Wrigthia arborea (Dennst.) Mabb. Bangl. Pharmaceut. J. 16(2), 211-216.

\section{How to cite this article:}

Ahirwar, P. K., Mishra, S. P., Pramod Kumar, 2020. Comparative evaluation of phytochemicals in leaf, stem bark and root bark of Holarrhena antidysenterica, Wrightia tomentosa and Wrightia tinctoria. Int.

J. Curr. Res. Biosci. Plant Biol. 7(10), 31-37. doi: https://doi.org/10.20546/ijcrbp.2020.710.004 